\title{
Research of Evaluation System for the Investment and Operational Efficiency of Distribution Network
}

\author{
Fangpeng Zheng ${ }^{1}$, Yongjun Wang ${ }^{1}$, Chunxue $\mathrm{Li}^{2,}{ }^{*}$ and Ming Zeng ${ }^{2}$ \\ ${ }^{1}$ Guizhou Power Grid Corporation, Guiyang, Guizhou, China \\ ${ }^{2}$ School of Economics and Management, North China Electric Power University, Beijing 102206, China \\ *Corresponding author
}

\begin{abstract}
The investment for distribution network construction is an important part of power grid construction. The establishment of analysis model for the investment and operational efficiency of distribution network construction is able to ensure the economic operation and reliability of power system, and has become a key method to the realization of the intensified grid construction. This paper has established the data envelopment analysis model and indicators about demand side response are added. The model is more scientific and accurate. Meanwhile, the practicality of this model has been proved through the example analysis.
\end{abstract}

Keywords-distribution network; investment and operational efficiency; data envelopment analysis model

\section{INTRODUCTION}

Throughout the current research situation in this field, the DEA model is widely used in power grid construction[1,2]. However, there is no research that analyze the investment and operational efficiency of distribution network by the combination of the DEA model[3]. The safe and stable operation of power distribution network that promoted by the implement of the demand side response is not considered as well[4-6]. Based on the lack of research above, this paper will establish a model that combines the DEA model with the entropy method. And a evaluation index system of the investment and operational efficiency of distribution network that is compatible with the demand side response will also be established. After that, the investment and operational efficiency of distribution network will be evaluated using the given model and index system.

\section{CONSTRUCTION OF EVAluation InDEX System}

The investment of the distribution network is the construction that adapts to the future city grid upgrades and satisfies the regional electricity demand. This paper will establish the evaluation system according to the economic indicators of the investment and operation of the distribution network, and the demand side response of users are also taken into account. The index system is given in TABLE I .

- Indicators of the distribution network investment. These indicators reflect the situation of the investment of the distribution network and the cost and benefit of the investment. Including the increased power supply for unit investment, the increased power supply for increased unit substation capacity, the investment payback period, NPV, IRR, etc.. Among them, the investment payback period, NPV and IRR take the annual average value of distribution network investment projects.

- Index of distribution network operation. These indicators reflect the operation of distribution network. Including the capacity-load rate, the line loss rate, the load forecast accuracy, etc..

- Index of demand side response. These indicators reflect the implement of demand response projects dominated by grid enterprises and their impacts on the operation of the distribution network. Including the added value of daily load rate on average, the maximum load reduction, the demand side response costs, the power system expansion investment that can be avoided, etc..

TABLE I. INVESTMENT AND OPERATIONAL EFFICIENCY EVALUATION SYSTEM.

\begin{tabular}{|c|c|}
\hline First Class Indicator & Second Class Indicator \\
\hline \multirow{4}{*}{$\begin{array}{c}\text { Distribution Network } \\
\text { Investment }\end{array}$} & $\begin{array}{c}\text { The Increased Power Supply for } \\
\text { Unit Investment }\end{array}$ \\
\cline { 2 - 2 } & $\begin{array}{c}\text { The Increased Power Supply for } \\
\text { Increased Unit Substation Capacity }\end{array}$ \\
\cline { 2 - 2 } & IRR \\
\cline { 2 - 2 } & Payback period \\
\cline { 2 - 2 } $\begin{array}{c}\text { Distribution Network } \\
\text { Operation }\end{array}$ & Nhe Capacity-load Rate \\
\cline { 2 - 2 } & The Line Loss Rate \\
\cline { 2 - 2 } & The Load Forecast Accuracy \\
\hline \multirow{3}{*}{$\begin{array}{c}\text { Demand Side Response } \\
\text { The Added Value of Daily Load } \\
\text { Rate on Average }\end{array}$} \\
\cline { 2 - 2 } & The Maximum Load Reduction \\
\cline { 2 - 2 } & The Demand Side Response Costs \\
\cline { 2 - 2 } & $\begin{array}{c}\text { The Power System Expansion } \\
\text { Investment That Can Be Avoided }\end{array}$ \\
\hline
\end{tabular}

\section{DEA MODELING}

DEA (Data Envelopment Analysis) is a non-parametric method that uses mathematical tools to evaluate the effectiveness of the production frontier of economic system. This method is suitable for the performance evaluation of multiple objective decision making units that are multiple-input and multiple-output. Based on relative efficiency, DEA method can evaluate the effectiveness of decision making units of the same type according to multiple indicators input and output. This paper uses DEA to evaluate investment and operational 
efficiency of distribution networks because of the better adaptability between them.

In data envelopment analysis, assume that there are t DMUs (Decision Making Unit) and each of them have $\mathrm{m}$ input variables and $n$ output variables. Among them, $X_{i k}$ stands for the input quantity of the $\mathrm{k}_{\mathrm{th}}$ DMU towards the $\mathrm{i}_{\text {th }}$ input variable. $y_{j k}$ stands for the output quantity of the $\mathrm{k}_{\mathrm{th}}$ DMU towards the $\mathrm{j}_{\text {th }}$ output variable. $O_{i}$ stands for the weight of the $\mathrm{i}_{\text {th }}$ input variable. $q_{j}$ stands for the weight of the $j_{\text {th }}$ output variable. e is the investment efficiency that needs solving. Each DMU has its corresponding efficiency evaluation indict, as the following equation:

$$
e_{k}=\frac{q^{T} y_{k}}{o^{T} x_{k}}=\frac{\sum_{j=1}^{n} q_{j} y_{j k}}{\sum_{i=1}^{m} o_{i} x_{i k}}, k=1,2, \cdots, t
$$

Constraint conditions is given as:

$$
\sigma . \tau .\left\{\begin{array}{l}
\frac{q^{T} y_{k}}{o^{T} x_{k}} \leq 1, k=1,2, \cdots, t \\
q \geq 0, o \geq 0, q \neq 0, o \neq 0 .
\end{array}\right.
$$

Perform Charnes-Cooper transform on it, let $v=\frac{1}{o^{T} x_{0}}>0, \quad \gamma=v \cdot o, \quad \sigma=v \cdot q$. Then original problem can be transformed into equivalent problem of inear programming. Just as the following equation:

$$
\begin{aligned}
& \max e_{k_{0}}=\sigma^{T} y_{0} \\
& \sigma . \tau .\left\{\begin{array}{l}
\gamma^{T} x_{k}-\sigma^{T} y_{k} \geq 0, k=1,2, \cdots, t, \\
\gamma^{T} x_{0}=1 \\
\gamma \geq 0, \quad \sigma \geq 0 .
\end{array}\right.
\end{aligned}
$$

Turn the function above into its dual programming and introduce slack variables as follows:

$$
\min \varepsilon
$$

$$
\text { s.t. }\left\{\begin{array}{l}
\sum_{k=1}^{t} \lambda_{k} x_{k}+r^{-}=\varepsilon x_{0} \\
\sum_{k=1}^{t} \lambda_{k} y_{k}-r^{+}=\varepsilon y_{0} \\
r^{-}, r^{+} \geq 0 \\
\lambda_{k} \geq 0, k=1, \cdots, t
\end{array}\right.
$$

Solve the linear programming model, get $\varepsilon$ is the investment and operational efficiency. $\varepsilon$ values $0 \leq \varepsilon \leq 1$, the lower value of $\varepsilon$, the lower efficiency is; the higher value of $\varepsilon$, the higher efficiency is. When $\varepsilon=1$, the efficiency of investment and operation is the highest, therefore, the optimal situation is achieved.

\section{EXAMPLES ANALYSIS}

\section{A. The Evaluation System After}

\section{B. Simplification}

As is discussed above, the index system after simplification is shown in TABLE II. Besides, according to the special requirements of DEA model, indicators are divided into input-indicator and output-indicator in this paper.

TABLE II. THE INDICATORS INVESTMENT EFFICIENCY EVALUATION SYSTEM (AFTER SIMPLIFICATION).

\begin{tabular}{|c|l|l|}
\hline $\begin{array}{c}\text { Code of } \\
\text { Indicators }\end{array}$ & \multicolumn{1}{|c|}{ Name of Indicators } & \multicolumn{1}{|c|}{$\begin{array}{c}\text { Kinds of } \\
\text { Indicators }\end{array}$} \\
\hline$I_{1}$ & $\begin{array}{l}\text { The Increased Power Supply for } \\
\text { Unit Investment }\end{array}$ & Output \\
\hline$I_{2}$ & $\begin{array}{l}\text { The Increased Power Supply for } \\
\text { Increased Unit Substation } \\
\text { Capacity }\end{array}$ & Output \\
\hline$I_{3}$ & Payback Period & Input \\
\hline$I_{4}$ & NPV & Input \\
\hline$I_{5}$ & The Capacity-load Rate & Input \\
\hline$I_{6}$ & The Line Loss Rate & Output \\
\hline$I_{7}$ & The Load Forecast Accuracy & Input \\
\hline$I_{8}$ & $\begin{array}{l}\text { The Added Value of Daily Load } \\
\text { Rate on Average }\end{array}$ & Output \\
\hline
\end{tabular}

Data of some cities in north China is given in TABLE III and IV. 
TABLE III. DATA FOR THE INDICATORS(1).

\begin{tabular}{|c|c|c|c|c|c|c|}
\hline Area & Year & $\begin{array}{c}\mathbf{I}_{1} /(\mathbf{k W} \cdot \mathbf{h} / \\
\text { RMB })\end{array}$ & $\mathbf{I}_{2} /(\mathbf{M W h} / \mathbf{M V A})$ & $\mathbf{I}_{3}$ & \begin{tabular}{|c}
$\mathbf{I}_{4} /($ million \\
yuan)
\end{tabular} & $\mathbf{I}_{5}$ \\
\hline \multirow{5}{*}{ A } & 2010 & 3.1 & 2676.2 & 13.41 & 4378.2 & 2.1 \\
\hline & 2011 & 2.2 & 2514.9 & 13.22 & 3217.1 & 2.5 \\
\hline & 2012 & 5.1 & 3292.6 & 13.78 & 3690.9 & 2.3 \\
\hline & 2013 & 7.4 & 2703.5 & 13.9 & 3729.3 & 2 \\
\hline & 2014 & 8.3 & 2564.6 & 14.55 & 4219.1 & 2.2 \\
\hline \multirow{5}{*}{ B } & 2010 & 1 & 1002.5 & 13.25 & 2563.3 & 1.9 \\
\hline & 2011 & 1.2 & 2101.3 & 14.21 & 3318.9 & 1.7 \\
\hline & 2012 & 1.6 & 902.3 & 13.22 & 2231.9 & 2.3 \\
\hline & 2013 & -2.5 & -101.2 & 14.64 & 2918.2 & 2.1 \\
\hline & 2014 & 0.5 & 2145.3 & 15.21 & 3011.1 & 2.2 \\
\hline \multirow{5}{*}{$\mathrm{C}$} & 2010 & 0.3 & 165.8 & 10.1 & 2846.3 & 2.5 \\
\hline & 2011 & 0.5 & 750.1 & 10.23 & 2910.4 & 2.6 \\
\hline & 2012 & 0.9 & 1511.4 & 10.5 & 3101.1 & 2.9 \\
\hline & 2013 & -1.5 & 1235.6 & 10.6 & 3210.2 & 2.2 \\
\hline & 2014 & 0.7 & 1451.7 & 11 & 2318.5 & 2.5 \\
\hline \multirow{5}{*}{$\mathrm{D}$} & 2010 & 2.6 & 1582.7 & 12.11 & 3819.2 & 1.9 \\
\hline & 2011 & 3.1 & 1286.2 & 11.67 & 4012.2 & 1.8 \\
\hline & 2012 & 3.7 & 1092 & 12.14 & 4110.3 & 1.6 \\
\hline & 2013 & 3.9 & 2590.7 & 12.15 & 4124.2 & 2.1 \\
\hline & 2014 & 3.5 & 3170.8 & 13.16 & 4510.3 & 2.3 \\
\hline
\end{tabular}

TABLE IV. DATA FOR THE INDICATORS(2).

\begin{tabular}{|c|c|c|c|c|c|c|}
\hline Area & Year & $\mathbf{I}_{6} / \%$ & $\mathbf{I}_{7} / \%$ & $\mathbf{I}_{8} / \%$ & $\mathbf{I}_{\mathbf{g}} / \mathbf{k W}$ & $\begin{array}{c}\mathbf{I}_{10} /(\text { million } \\
\text { yuan) } \\
\end{array}$ \\
\hline \multirow{5}{*}{ A } & 2010 & 4.2 & 96.2 & 4.3 & 57.4 & 16.2 \\
\hline & 2011 & 4.6 & 95.1 & 3.1 & 59.3 & 14.1 \\
\hline & 2012 & 4.9 & 96.3 & 3.2 & 62.4 & 16.2 \\
\hline & 2013 & 5.1 & 97.2 & 3.9 & 67.3 & 25.2 \\
\hline & 2014 & 4.8 & 98.3 & 3.7 & 88.3 & 36.7 \\
\hline \multirow{5}{*}{ B } & 2010 & 5.1 & 93.2 & 4.1 & 23.4 & 10.2 \\
\hline & 2011 & 4.9 & 94.1 & 4.4 & 25.7 & 8.3 \\
\hline & 2012 & 4.8 & 93.3 & 3.2 & 21.5 & 8.9 \\
\hline & 2013 & 4.5 & 95.1 & 3.6 & 22.4 & 9.2 \\
\hline & 2014 & 4.7 & 96.2 & 3.3 & 25.3 & 8.4 \\
\hline \multirow{5}{*}{$\mathrm{C}$} & 2010 & 5.4 & 97.9 & 2.9 & 31.7 & 10.2 \\
\hline & 2011 & 5.7 & 93.2 & 2.7 & 28.1 & 11.1 \\
\hline & 2012 & 5.3 & 94.1 & 3.3 & 29 & 12.3 \\
\hline & 2013 & 5.1 & 95.2 & 3.6 & 41 & 13.2 \\
\hline & 2014 & 5 & 94.4 & 3.8 & 45.6 & 14.6 \\
\hline
\end{tabular}

\begin{tabular}{|c|c|c|c|c|c|c|}
\hline \multirow{5}{*}{$\mathrm{D}$} & 2010 & 4.5 & 98.1 & 4.1 & 62.34 & 21.4 \\
\cline { 2 - 7 } & 2011 & 4.3 & 98.2 & 4.4 & 71.2 & 23.6 \\
\cline { 2 - 7 } & 2012 & 4.6 & 97.6 & 4.5 & 77.9 & 22.7 \\
\cline { 2 - 7 } & 2013 & 4.8 & 97.2 & 4.2 & 82.1 & 34.2 \\
\hline & 2014 & 4.9 & 97.9 & 3.9 & 83.2 & 33.1 \\
\hline
\end{tabular}

\section{DEA Result}

Input data from TABLE III and IV into the model established above, the weight of each indicator is obtained through the entropy weight method, as is shown in TABLE V. Use the saddle point algorithm for optimization, the distribution network investment and operational efficiency of the four cities from 2010-2014 is obtained, as is shown in TABLE V. And Specific investment efficiency trends can be seen in Fig.1.

The results of data envelopment analysis of $\mathrm{ABCD}$, four cities are shown in TABLE V.

TABLE V. THE RESULT OF DATA ENVELOPMENT ANALYSIS.

\begin{tabular}{|c|c|c|}
\hline City & Year & Investment Efficiency \\
\hline \multirow{4}{*}{ A } & 2010 & 0.377 \\
\cline { 2 - 3 } & 2011 & 0.708 \\
\cline { 2 - 3 } & 2012 & 0.858 \\
\cline { 2 - 3 } & 2013 & 0.826 \\
\cline { 2 - 3 } & 2014 & 1.000 \\
\hline \multirow{4}{*}{ B } & 2010 & 0.294 \\
\cline { 2 - 3 } & 2011 & 0.467 \\
\cline { 2 - 3 } & 2012 & 0.416 \\
\cline { 2 - 3 } & 2013 & 0.280 \\
\hline \multirow{4}{*}{ C } & 2014 & 0.449 \\
\cline { 2 - 3 } & 2010 & 0.413 \\
\cline { 2 - 3 } & 2011 & 0.397 \\
\cline { 2 - 3 } & 2012 & 0.443 \\
\cline { 2 - 3 } & 2013 & 0.425 \\
\hline \multirow{4}{*}{ D } & 2014 & 0.484 \\
\cline { 2 - 3 } & 2010 & 0.734 \\
\cline { 2 - 3 } & 2011 & 0.833 \\
\cline { 2 - 3 } & 2012 & 0.885 \\
\cline { 2 - 3 } & 2013 & 0.896 \\
\hline
\end{tabular}

Judging from the results, gaps of investment and operational efficiency between these four cities are large. Compared with other three cities, City D has been at a relatively high level; City A had its efficiency greatly improve in 2011. And in 2014, optimum was achieved. Therefore, the investment and operational efficiency of City A in 2014 can be regarded as the benchmarking for calibration management. Because of the large rate of rural network, the efficiency of City $\mathrm{C}$ and $\mathrm{D}$ are low.

\section{CONCLUSIONS}

With the development of economic and society, demand for electricity has steadily increased. The construction of power grid, especially the planning and investment of the distribution network, is significant to the development of power industry in the future. In this paper, an evaluation model for the investment and operational efficiency of distribution network based on DEA is established. The entropy weight method is used to give weight indicators scientifically, and measure input and output 
data for the investment and operation of distribution network. Also, the demand side response is brought into the system to evaluate investment and operational efficiency of distribution networks. It's proved by the analysis of examples that the result of the evaluation system is precise, objective and practical. The model can be used to evaluate investment and operational efficiency of distribution networks of power grid enterprises and promote them to develop DSM work.

\section{REFERENCES}

[1] Sergey S, Kweku-Muata O. Using Data Envelopment Analysis (DEA) for monitoring efficiency-based performance of productivity-driven organizations: Design and implementation of a decision support system[J]. Omega, 2013, 41(1): 131-142.

[2] Aydın Ç, Neşe Y. Performance assessment of Turkish electricity distribution utilities: An application of combined FAHP/TOPSIS/DEA methodology to incorporate quality of service[J]. Utilities Policy, 2011, 23: 59-71

[3] Azadeh A, Ghaderi S, Omrani H et al. An integrated DEA-COLS-SFA algorithm for optimization and policy making of electricity distribution units[J]. Energy Policy, 2009, 37(7): 2605-2618.

[4] Xie Chuansheng, Dong Dapeng, Hua Shengping et al. Safety Evaluation of Smart Grid based on AHP-Entropy Method [J]. Systems Engineering Procedia, 2012, 4: 203-209.

[5] Li Jun, Li Jiguang, Yao Jiangang, et al. Application of Attribute Recognition and G1-Entropy Method in Evaluation of Power Quality[J]. Power System Technology, 2009, 33(14): 56-61 (in Chinese).

[6] Wang Jianchong, Research and application on the evaluation of the investment benefit of grid enterprise[D]. Beijing: North China Electric Power University, 2010. (in Chinese).

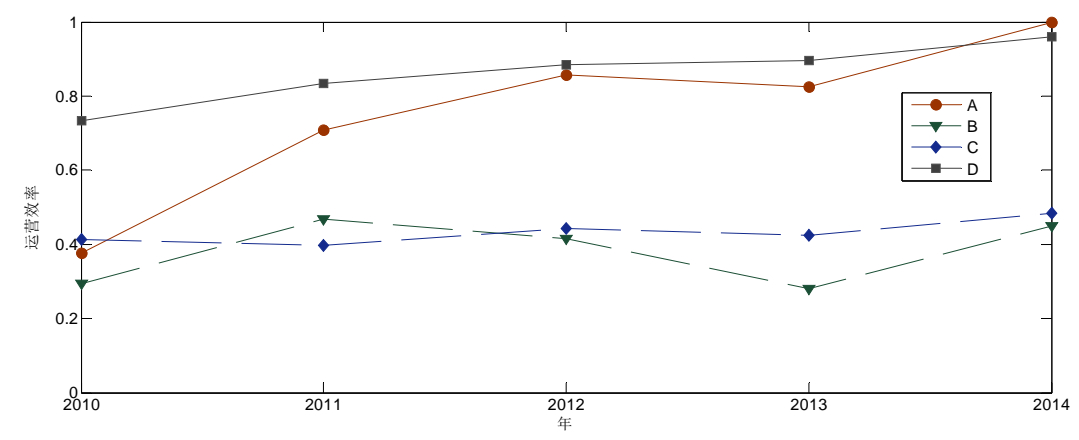

FIGURE I. TREND OF OPERATIONAL EFFICIENCY. 